\title{
IRIS)
}

\section{Informação e conhecimento na vivência social das cidades: um caminho para a sustentabilidade ambiental}

\section{Information and knowledge in the social experience of cities: a path to environmental sustainability}

\author{
Frederico Cordeiro Martins \\ Doutorando em Sistemas de Informação e Gestão do Conhecimento pela Fundação Universidade Mineira \\ de Educação e Cultura, Minas Gerais, Brasil \\ frederico.cordeiro.martins@gmail.com \\ Priscila Reis dos Santos \\ Doutoranda em Sistemas de Informação e Gestão do Conhecimento pela Fundação Universidade Mineira \\ de Educação e Cultura, Minas Gerais, Brasil \\ priscila@fumec.br
}

\begin{abstract}
Resumo: Trata-se de um ensaio teórico para compreensão das contribuições científicas da ciência da informação na vivência social das cidades como instrumento voltado para sustentabilidade ambiental e que preencha as lacunas omissivas das instituições, Institutional Void, no tocante às políticas públicas da gestão de resíduos sólidos. É problematizado a partir dos transtornos vivenciados pelas cidades em relação aos resíduos sólidos, nas omissões da gestão ambiental do poder público municipal e na necessidade de desenvolvimento sustentável. Para elaboração, além da literatura clássica, foram estudados artigos publicados em periódicos, levantados por procedimento de busca no Portal de Periódicos da CAPES e da Scielo, com termos combinados a partir da utilização de operadores Booleanos, em português, inglês e espanhol, nos últimos cinco anos, considerados apenas os artigos cujo texto completo estivesse disponível. A pesquisa possibilitou estabelecer uma relação entre os temas para criar uma base conceitual necessária ao desenvolvimento de estudos empíricos voltados para a sustentabilidade ambiental a partir da informação e do conhecimento na vivência social.
\end{abstract}

Palavras-chave: Informação. Cidades. Institutional Void. Resíduos sólidos. Sustentabilidade.

\begin{abstract}
This is a theoretical essay for understanding the scientific contributions of information science in the social experience of cities as an instrument focused on environmental sustainability and filling the omissive gaps of institutions, Institutional Void, regarding public policies of solid waste management. It is problematized from the disturbances experienced by cities in relation to solid waste, the omissions of environmental management of the municipal government and the need for sustainable development. For elaboration, besides the classic literature, articles published in journals, surveyed by the CAPES and Scielo Journal Portal, were studied, with terms combined from the use of Boolean operators, in Portuguese, English and Spanish, in the last five years, considering only articles whose full text was available. The research made it possible to establish a relationship between the themes to create a conceptual basis necessary for the development of empirical studies focused on environmental sustainability based on information and knowledge in social experience.
\end{abstract}



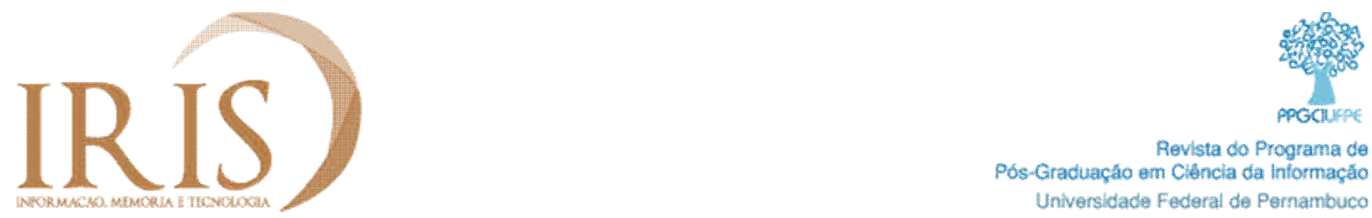

Keywords: Information. Cities. Institutional Void. Solid waste. Sustainability.

\section{Introdução}

$\mathrm{Na}$ atualidade, as cidades vêm apresentando um exponencial crescimento nos problemas ambientais relacionados com as suas atividades econômicas, interações sociais e culturais em face de diversos fatores como o crescimento populacional e o aumento do consumo, o que faz com que as questões ambientais recebam especial atenção dos meios diplomáticos de integração de países em tratados internacionais e das políticas nacionais, com objetivo de mitigar os efeitos da produção e consumo no meio-ambiente.

Além de esforços políticos, vivemos em um cenário onde se observa uma necessidade de desenvolvimento de ações de responsabilidade social em níveis e escalas menores, individuais, regionais e institucionais, na busca da denominada sustentabilidade ambiental, uma concepção complexa que visa garantir compatibilidade entres as dimensões econômica, social e ambiental.

Segundo dados fornecidos pela Organização das Nações Unidas-ONU, em 1950 a população mundial era estimada em cerca de 2,6 bilhões de pessoas, em 1990, 5,3 bilhões e, em 2015, 7,3 bilhões, ou seja, uma expansão rápida que traz importantes implicações na vida das pessoas e suas relações com o ambiente onde vivem.

A “DECLARAÇÃO DE QUITO SOBRE CIDADES E AGLOMERADOS URBANOS SUSTENTÁVEIS PARA TODOS”, produzida durante Conferência das Nações Unidas sobre Habitação e Desenvolvimento Urbano Sustentável (Habitat III) de 17 a 20 de outubro de 2016, em Quito, Equador destaca que "até 2050, espera-se que a população urbana quase duplique fazendo da urbanização uma das mais transformadoras tendências do Século XXI.” (ONU, 2016, p. 3).

O Gráfico 1 demonstra um projeção da população mundial até 2100, onde se estima que o planeta abrigue cerca de 11,2 bilhões de habitantes, uma cifra assustadora do ponto de vista ambiental. 


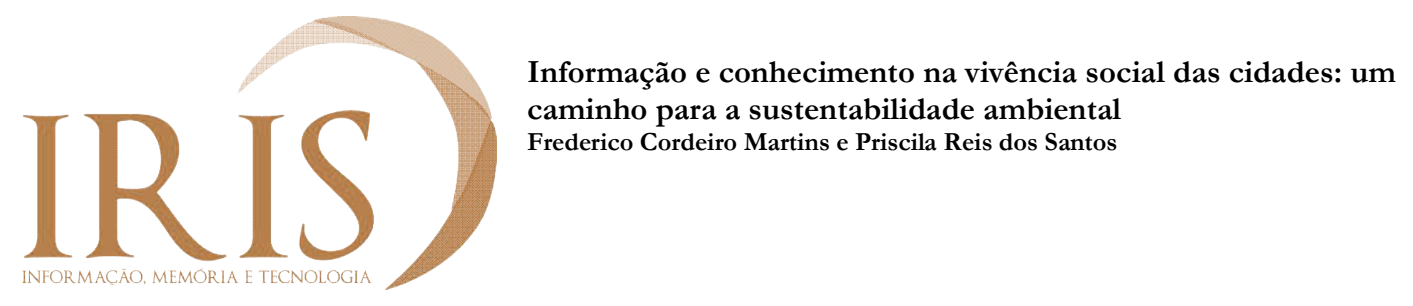

Gráfico 1 - Organização das Nações Unidas-ONU

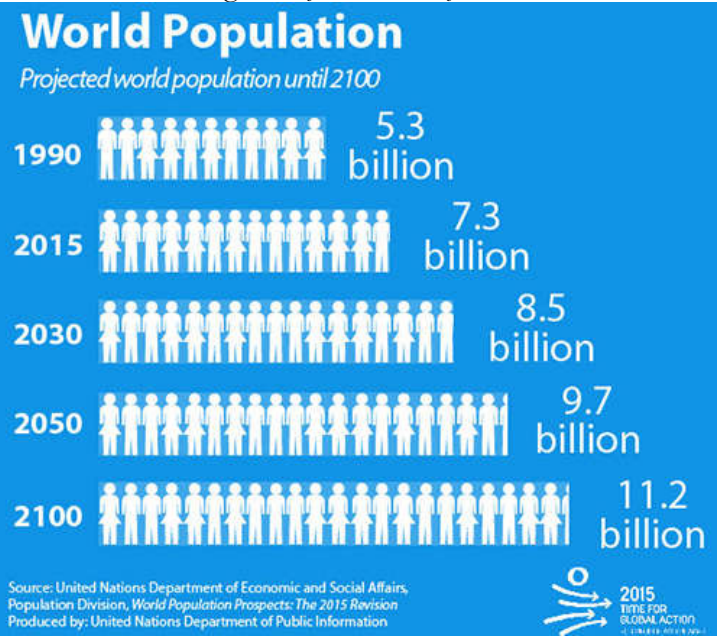

Fonte: ONU, $2019^{1}$.

Este crescimento populacional, aliado às atividades econômicas, interações sociais e culturais e os impactos ambientais se concentram cada vez mais nas cidades e são grandes desafios para o desenvolvimento sustentável (ONU, 2016, p. 3), dentre eles a geração de resíduos sólidos e suas formas de gerenciamento.

Segundo estudo realizado pela Associação Brasileira de Empresas de Limpeza Pública e Resíduos Especiais (Abrelpe) (2017, p. 15) “a população brasileira apresentou um crescimento de 0,75\% entre 2016 e 2017, enquanto a geração per capita de RSU apresentou aumento de 0,48\% A geração total de resíduos aumentou 1\% no mesmo período, atingindo um total de 214.868 toneladas diárias de RSU no país.”

Esta constatação conduz ao fato de que a gestão do lixo é um problema mundial que clama por soluções urgentes, em especial aquelas que se desenvolvem a nível regional. As cidades precisam de uma gestão eficiente de resíduos sólidos para que consiga garantir um ambiente capaz de abrigar toda sua população sem riscos e, considerando que sua responsabilidade é legalmente atribuída ao poder público municipal como forma prioritária, o tema deve ser pautado como prioritário nas agendas locais que vem buscando por meio da informação e do conhecimento desenvolver técnicas inovadoras de gestão ambiental, embora em pouca sintonia com os cidadãos, cuja articulação se torna fundamental para o sucesso das políticas públicas destinadas a este setor.

Destacado por Polizelli (2011) como o "paradigma da gestão do conhecimento" a transição para o século XXI apresenta um novo momento da gestão ambiental, onde se verifica de maneira mais ativa os vínculos da administração, conhecimento e meio ambiente, uma nova abordagem das 


\section{IRIS}

Informação e conhecimento na vivência social das cidades: um

caminho para a sustentabilidade ambiental

Frederico Cordeiro Martins e Priscila Reis dos Santos

tecnologias de informação e conhecimento permite que os cidadãos se organizem numa ampla articulação em torno das políticas públicas de seus interesses para a criação de agendas próprias. Para Polizelle (2011, p. XXII) "Essa integração em escala tão ampla denomina-se Sociedade da Informação".

A Política Nacional de Resíduos Sólidos - PNRS (Lei no 12.305/2010) estabelece um rol de instrumentos necessários para o alcance dos objetivos da política, ressaltando entre eles, os planos de resíduos sólidos como um dos principais instrumentos, o que exigiu de cada cidade a elaboração de um plano pertinente.

Contudo, a tradução das políticas públicas em planos de ações de planejamento, controle e avaliação se mostram ainda relativamente incipientes ao considerarmos a complexidade e relevância das questões envolvidas e a ineficácia das instituições políticas o que nos leva à hipótese de que a influência das tecnologias de informação e comunicação na sociedade e instituições, com foco nas cidades e nas pessoas pode contribuir neste sentido.

\subsection{Problema de pesquisa}

Considerando a ineficácia do aparato institucional e a necessidade de desenvolvimento das cidades frente aos problemas ambientais que surgem a partir da geração de resíduos sólidos é possível garantir a gestão ambiental sustentável, completando as lacunas deixadas pelas instituições políticas, a partir da informação e o conhecimento na vivência social e sua relação de cuidado com a cidade?

Diante deste cenário, surge a importância de se verificar a relação das cidades e seus moradores com os resíduos sólidos e suas formas de gerenciamento, em especial quanto à adoção de abordagens baseadas nas tecnologias de informação e conhecimento que transformem as políticas públicas ambientais em planejamento, ação, controle e avaliação.

\subsection{Objetivo}

O objetivo geral deste trabalho é de compreender quais são as contribuições científicas da ciência da informação na vivência social das cidades, que preencham as lacunas omissivas das instituições, Institutional Void, no tocante às políticas públicas da gestão de resíduos sólidos, para que, assim, seja 
IRIS

Informação e conhecimento na vivência social das cidades: um

caminho para a sustentabilidade ambiental

Frederico Cordeiro Martins e Priscila Reis dos Santos

possível criar uma base conceitual sólida necessária ao desenvolvimento de estudos empíricos para apresentação de arquétipos de aplicação prática em ciência, tecnologia e inovação, voltados para a sustentabilidade ambiental, como o monitoramento da geração de resíduos e ações ligadas à sua adequação, descarte, coleta espontânea e destinação correta.

\section{Metodologia}

Para elaboração do ensaio teórico, foi realizada uma revisão da literatura embasada no objetivo principal, mediante o uso de palavras chaves em processos de busca estruturada em bases científicas que reúnem de maneira ordenada diversos estudos que tratam das questões aqui pesquisadas, sua correlação entre as várias teorias, para gerar um arcabouço de informações que venha auxiliar os futuros estudos, identificando os conteúdos, métodos e tendências das publicações (WENDLER, 2012).

A pesquisa sistemática objetiva a criação de uma estrutura procedimental para garantir a qualidade credibilidade das fontes de informação e que a pesquisa esteja de acordo com os critérios definidos.

No procedimento de busca foi utilizada a biblioteca digital, Portal de Periódicos da CAPES e a Plataforma Scielo, com aplicação de operadores lógicos booleanos, nos idiomas português, inglês e espanhol, no período compreendido entre os últimos cinco anos, considerando apenas os artigos cujo texto completo estivesse disponível.

Os operadores lógicos booleanos são atribuídos a George Boole (1815- 1864), matemático e lógico britânico que desenvolveu a teoria da lógica binária (valores 0 ou 1, falso ou verdadeiro), que foi aplicada ao funcionamento dos circuitos eletrônicos e na arquitetura dos computadores. Consiste, então, em um sistema de recuperação de informação baseado na combinação de dois ou mais termos ligados por operadores lógicos (AND, OR e NOT) que transforma a busca em algo mais restrito ou detalhado.

Os resultados foram sintetizados nas Tabelas 1 e 2. 
Informação e conhecimento na vivência social das cidades: um caminho para a sustentabilidade ambiental

Frederico Cordeiro Martins e Priscila Reis dos Santos

Tabela 1 - Buscas Portal de Periódicos da CAPES

\begin{tabular}{|c|c|c|c|c|c|c|c|}
\hline BUSCA & TERMOS & $\begin{array}{l}\text { OPERADOR } \\
\text { LÓGICO } \\
\text { BOOLEANO }\end{array}$ & $\begin{array}{c}\text { IDIOMAS } \\
\text { DE } \\
\text { BUSCA }\end{array}$ & TIPO & PERÍODO & $\mid \begin{array}{c}\text { BIBLIOTECA } \\
\text { DIGITAL }\end{array}$ & RESULTADOS \\
\hline 1 & $\begin{array}{c}\text { Informação } \\
\text { Conhecimento } \\
\text { Vivência social } \\
\text { Cidades } \\
\text { Sustentabilidade } \\
\text { ambiental } \\
\text { Resíduos sólidos } \\
\text { Vazios } \\
\text { instituicionais } \\
\end{array}$ & AND & $\begin{array}{l}\text { Português } \\
\text { Inglês } \\
\text { Espanhol }\end{array}$ & $\begin{array}{c}\text { Artigo } \\
\text { texto } \\
\text { completo }\end{array}$ & 2014 a 2018 & Capes & 0 \\
\hline 2 & $\begin{array}{c}\text { Informação } \\
\text { Conhecimento } \\
\text { Vivência social } \\
\text { Cidades } \\
\text { Sustentabilidade } \\
\text { ambiental } \\
\text { Resíduos sólidos } \\
\end{array}$ & AND & $\begin{array}{l}\text { Português } \\
\text { Inglês } \\
\text { Espanhol }\end{array}$ & $\begin{array}{c}\text { Artigo } \\
\text { texto } \\
\text { completo }\end{array}$ & 2014 a 2018 & Capes & 2 \\
\hline 3 & $\begin{array}{c}\text { Informação } \\
\text { Conhecimento } \\
\text { Vivência social } \\
\text { Cidades } \\
\text { Sustentabilidade } \\
\text { ambiental } \\
\end{array}$ & AND & $\begin{array}{l}\text { Português } \\
\text { Inglês } \\
\text { Espanhol }\end{array}$ & $\begin{array}{c}\text { Artigo } \\
\text { texto } \\
\text { completo }\end{array}$ & 2014 a 2018 & Capes & 16 \\
\hline 4 & $\begin{array}{c}\text { Informação } \\
\text { Conhecimento } \\
\text { Cidades } \\
\text { Sustentabilidade } \\
\text { ambiental } \\
\text { Resíduos sólidos } \\
\text { Políticas públicas } \\
\end{array}$ & AND & $\begin{array}{l}\text { Português } \\
\text { Inglês } \\
\text { Espanhol }\end{array}$ & $\begin{array}{c}\text { Artigo } \\
\text { texto } \\
\text { completo }\end{array}$ & 2014 a 2018 & Capes & 34 \\
\hline 5 & $\begin{array}{c}\text { Vazios } \\
\text { Institucionais } \\
\text { Institutional voids } \\
\text { Políticas públicas }\end{array}$ & $\begin{array}{c}\text { OR } \\
\text { AND }\end{array}$ & $\begin{array}{l}\text { Português } \\
\text { Inglês } \\
\text { Espanhol }\end{array}$ & $\begin{array}{c}\text { Artigo } \\
\text { texto } \\
\text { completo }\end{array}$ & 2014 a 2018 & Capes & 55 \\
\hline
\end{tabular}

Fonte: Elaborada pelos autores, 2019.

Tabela 2-Buscas Plataforma Scielo

\begin{tabular}{|c|c|c|c|c|c|c|c|}
\hline BUSCA & TERMOS & $\begin{array}{l}\text { OPERADOR } \\
\text { LÓGICO } \\
\text { BOOLEANO }\end{array}$ & $\begin{array}{l}\text { IDIOMAS } \\
\text { DE BUSCA }\end{array}$ & TIPO & PERÍODO & $\begin{array}{l}\text { BIBLIOTECA } \\
\text { DIGITAL }\end{array}$ & RESULTADOS \\
\hline 1 & $\begin{array}{c}\text { gestão } \\
\text { ambiental } \\
\text { resíduos sólidos }\end{array}$ & AND & $\begin{array}{l}\text { Português } \\
\text { Inglês } \\
\text { Espanhol }\end{array}$ & $\begin{array}{c}\text { Artigo } \\
\text { texto } \\
\text { completo }\end{array}$ & 2014 a 2018 & Scielo & 1 \\
\hline 2 & $\begin{array}{l}\text { informação } \\
\text { conhecimento } \\
\text { cidades }\end{array}$ & AND & $\begin{array}{l}\text { Português } \\
\text { Inglês } \\
\text { Espanhol }\end{array}$ & $\begin{array}{c}\text { Artigo } \\
\text { texto } \\
\text { completo }\end{array}$ & 2014 a 2018 & Scielo & 78 \\
\hline 3 & $\begin{array}{c}\text { cidades } \\
\text { sustentabilidade } \\
\text { ambiental }\end{array}$ & AND & $\begin{array}{l}\text { Português } \\
\text { Inglês } \\
\text { Espanhol }\end{array}$ & $\begin{array}{c}\text { Artigo } \\
\text { texto } \\
\text { completo }\end{array}$ & 2014 a 2018 & Scielo & 84 \\
\hline 4 & $\begin{array}{c}\text { cidades resíduos } \\
\text { sólidos políticas } \\
\text { públicas }\end{array}$ & AND & $\begin{array}{l}\text { Português } \\
\text { Inglês } \\
\text { Espanhol }\end{array}$ & $\begin{array}{c}\text { Artigo } \\
\text { texto } \\
\text { completo }\end{array}$ & 2014 a 2018 & Scielo & 30 \\
\hline 5 & $\begin{array}{c}\text { Vazios } \\
\text { Institucionais } \\
\text { Institutional } \\
\text { voids Políticas } \\
\text { públicas }\end{array}$ & $\begin{array}{c}\text { OR } \\
\text { AND }\end{array}$ & $\begin{array}{l}\text { Português } \\
\text { Inglês } \\
\text { Espanhol }\end{array}$ & $\begin{array}{c}\text { Artigo } \\
\text { texto } \\
\text { completo }\end{array}$ & 2014 a 2018 & Scielo & 1 \\
\hline
\end{tabular}

Fonte: Elaborada pelos autores, 2019. 


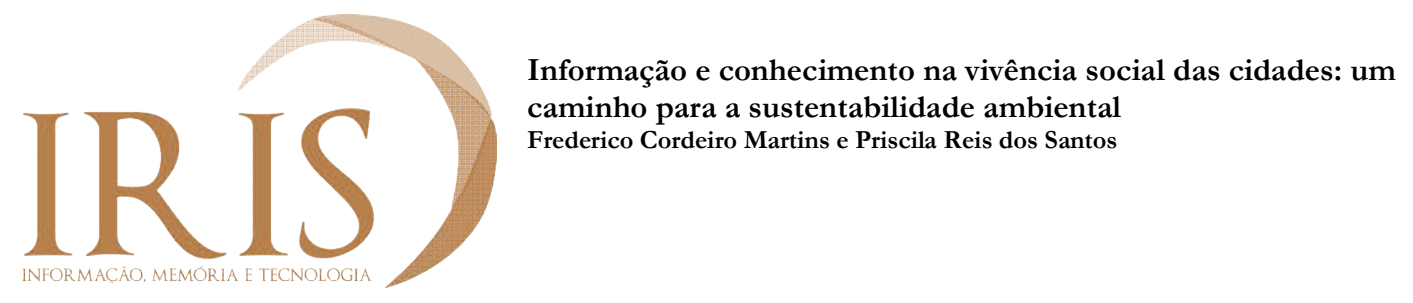

A interdisciplinaridade na pesquisa busca a correta contextualização de certas realidades marcadas pela complexidade, pois na maioria das vezes não podem ser explicadas por uma única disciplina (MARANHÃO, 2010).

Diante da complexidade de que se tratam os temas encontra-se na cooperação científica, além do estudo de diversas áreas de conhecimento, a correta investigação das prováveis soluções para os problemas advindos desta intrincada relação.

Para não restringir o estudo aos textos que pura simplesmente continham os descritores previamente definidos na pesquisa, a partir de uma leitura sistemática dos conteúdos utilizou-se como critérios de exclusão ou inclusão, aqueles que apresentavam contribuições científicas relativas às ciências da informação e gestão do conhecimento, conceitos teóricos clássicos, dos problemas enfrentados pelas cidades no gerenciamento de resíduos sólidos e na sua ausência por parte das instituições políticas (Institutional Voids), nos mecanismos de transferência de informação e conhecimento social e na sustentabilidade ambiental.

Esta análise se encontra sintetizada na Tabela 3. 
Informação e conhecimento na vivência social das cidades: um caminho para a sustentabilidade ambiental

Frederico Cordeiro Martins e Priscila Reis dos Santos

Tabela 3 - Principais contribuições científicas

\begin{tabular}{|c|c|c|c|c|c|c|}
\hline & título & AUTORES & PUBLICAÇão & OBJETIVO/FOCO DO ESTUDO & METODOLOGIA & PRINCIPAIS CONSTRUTOS \\
\hline 1 & $\begin{array}{l}\text { A proteção ambiental e a gestão } \\
\text { compartilhada: um estudo de caso na } \\
\text { Regiâa Metropolitana de Natal }\end{array}$ & $\begin{array}{l}\text { Raquel Maria da Costa Silveira } \\
\text { Fábio Fonseca Figueiredo } \\
\text { Jelisse Vieira Gomes Almeida }\end{array}$ & $\begin{array}{l}\text { Cad. Metrop., Säo Paulo, v. } \\
\text { 20, n. 42, pp. 513-530, } \\
\text { maio/ago 2018 } \\
\text { http:///dx.doi.org/10.1590/22 } \\
\text { 36-9996.2018-4210 }\end{array}$ & $\begin{array}{l}\text { Refletir acerca da relação } \\
\text { entre a Política Nacional de } \\
\text { Resíduos Sólidos e o Estatuto } \\
\text { da Metrópole, } \\
\text { compreendendo as } \\
\text { implicaçōes e os desafios } \\
\text { previstos nessas normas para } \\
\text { as regiôes metropolitanas no } \\
\text { Brasil }\end{array}$ & \begin{tabular}{|l} 
Estudo de caso na \\
Região \\
Metropolitana de \\
Natal (RMN) \\
\\
\end{tabular} & $\begin{array}{l}\text { Desafios da gestão } \\
\text { metropolitana no Brasil } \\
\text { Política ancional de } \\
\text { residuos sólidos e suas } \\
\text { implicaçôes nas regiỗes } \\
\text { metropolitanas. }\end{array}$ \\
\hline 2 & \begin{tabular}{|l|} 
Gestão de resíduos sólidos urbanos \\
nos municipios da Bacia Hidrográfica \\
do Alto Tietê̂: uma análise sobre o uso \\
de TIC no acesso à informaçăo \\
governamental
\end{tabular} & $\begin{array}{l}\text { Flávio Bordino Klein Sylmara } \\
\text { Lopes Francelino Gonçalves- } \\
\text { Dias Martin Jayo }\end{array}$ & $\begin{array}{l}\text { Revista Brasileira de Gestão } \\
\text { Urbana (Brazilian Journal of } \\
\text { Urban Management), } 2018 \\
\text { jan./abr., 10(1), 140-153 }\end{array}$ & $\begin{array}{l}\text { Analisar de que forma } \\
\text { tecnologias de informação e } \\
\text { comunicaçăo (TIC), e a } \\
\text { internet em particular, são } \\
\text { empregadas para apoiara a } \\
\text { gestão de ersiduos sólidos } \\
\text { urbanos (RSU) no nivel } \\
\text { municipal. }\end{array}$ & $\begin{array}{l}\text { Pesquisa } \\
\text { exploratória, de } \\
\text { natureza } \\
\text { qualitativa. }\end{array}$ & $\begin{array}{l}\text { Resíduos sólidos urbanos, } \\
\text { impactos ambientais e } \\
\text { estratégias de gestão. } \\
\text { Groverno eletrônico e o } \\
\text { acesso à informação. }\end{array}$ \\
\hline 3 & $\begin{array}{l}\text { Contribuiç̧̃es para a evolução do } \\
\text { gerenciamento de resíduos sólidos } \\
\text { urbanos no Brasil com base na } \\
\text { experiência Européia }\end{array}$ & $\begin{array}{l}\text { Camille Ferreira Mannarino } \\
\text { João Alberto Ferreira } \\
\text { Mauro Gandolla }\end{array}$ & $\begin{array}{l}\text { Eng Sanit Ambient | v.21 n.2 } \\
\text { | abr/jun 2016 | 379-385 }\end{array}$ & $\begin{array}{l}\text { Apresentar dados relevantes } \\
\text { sobre ogerenciamento de } \\
\text { resíduos sólidos urbanos } \\
\text { (RSU) na Europa de forma a } \\
\text { se estabelecer paralelos e } \\
\text { subsidiar a discussão no } \\
\text { Brasil. }\end{array}$ & $\begin{array}{l}\text { Não foi esclare cida } \\
\text { corretamente }\end{array}$ & $\begin{array}{l}\text { Gestão de resíduos } \\
\text { sólidos como parte do } \\
\text { planejamento urbano. }\end{array}$ \\
\hline 4 & \begin{tabular}{|l|} 
Social innovation as a process to \\
overcome institutional voids: a \\
multididimensional overview Inovação \\
social como processo de superação de \\
vazios institucionais: uma visão \\
multidimensional
\end{tabular} & \begin{tabular}{|l} 
MANUELA RÖSING AGOSTINI \\
LUCIANA MARQUES VIEIRA \\
MARILA BONZANINI BOSSLE \\
\end{tabular} & $\begin{array}{l}\text { RAM, REV. ADM. MACKENZIE, } \\
\text { (Mackenzie Management } \\
\text { Review) } 17(6) \text {, Special } \\
\text { Edition • SÃO PAULO, SP • } \\
\text { NOV./DEC. 2016 •ISSN 1518- } \\
6776 \text { (printed version) •ISSN } \\
1678-6971\end{array}$ & $\begin{array}{l}\text { Propose a theoretical } \\
\text { framework to explore social } \\
\text { innovation as a response to } \\
\text { institutional voids in a } \\
\text { multidimensional analysis. } \\
\text { Propor um quadro teorico } \\
\text { para explorar a inovação } \\
\text { social como uma resposta a } \\
\text { vazios institucionais em uma } \\
\text { análise multidimensional. }\end{array}$ & $\begin{array}{l}\text { Literature review. } \\
\text { Revisão de } \\
\text { literatura. }\end{array}$ & $\begin{array}{l}\text { Social Innovation. } \\
\text { Inovação social. }\end{array}$ \\
\hline 5 & $\begin{array}{l}\text { Construindo governança eletrônica de } \\
\text { cidades.Um modelo de } \\
\text { implementação de soluções para } \\
\text { inovação e otimizaçăo da gestão } \\
\text { pública }\end{array}$ & $\begin{array}{l}\text { Gilberto dos Santos Madeira } \\
\text { Tor Guimaraes } \\
\text { Leonardo de Souza Mendes }\end{array}$ & $\begin{array}{l}\text { Revista de GESTÃO dos } \\
\text { Países de Língua Portuguesa }\end{array}$ & $\begin{array}{l}\text { Desenvolver e propor um } \\
\text { modelo para implementação } \\
\text { de governança eletrônica de } \\
\text { cidades. }\end{array}$ & Sequencial & $\begin{array}{l}\text { Efe tividade da } \\
\text { implementaçăo de } \\
\text { inovação municipal }\end{array}$ \\
\hline 6 & $\begin{array}{l}\text { Factores de desarrollo de las ciudades } \\
\text { inteligentes }\end{array}$ & Dorota Sikora - Fernández & $\begin{array}{l}\text { Revista Universitaria de } \\
\text { Geografía / ISSN 0326-8373 / } \\
\text { 2017, } 26 \text { (1), 135-152 }\end{array}$ & $\begin{array}{l}\text { Responder a las preguntas } \\
\text { acerca de cuáles son los } \\
\text { factores de la creación y } \\
\text { funcionamiento de las } \\
\text { ciudades inteligentes y si es } \\
\text { una necesidad para el } \\
\text { desarrollo de áreas banizadas } \\
\text { o bien, si es una nueva moda } \\
\text { para poner una etiqueta a la } \\
\text { ciudad, utilizada por las } \\
\text { autoridades locales, para } \\
\text { crear una imagen de la } \\
\text { misma. }\end{array}$ & Estudo de caso & Soluciones inteligentes \\
\hline & \begin{tabular}{|} 
A agregação das Tecnologias de \\
Informaçăo e Comunicaçăo ao espaço \\
público urbano: reflexōes em torno \\
do Projeto CyberParks
\end{tabular} & $\begin{array}{l}\text { Carlos Smaniotto Costa } \\
\text { Marluci Menezes }\end{array}$ & $\begin{array}{l}\text { Revista Brasileira de Gestão } \\
\text { Urbana (Brazilian Journal of } \\
\text { Urban Management), } 2016 \\
\text { set./dez., 8(3), 332-344 }\end{array}$ & $\begin{array}{l}\text { Investigar a contribuição das } \\
\text { TiC na transformação das } \\
\text { cidades em contextos mais } \\
\text { inclusivos, e não somente } \\
\text { mais high tech. }\end{array}$ & Estudo de caso & $\begin{array}{l}\text { Análise de Projeto } \\
\text { denominado CyberParks }\end{array}$ \\
\hline 8 & $\begin{array}{l}\text { INFORMAÇÃO, CIDADE E } \\
\text { CONHECIMENTO: POR UMA } \\
\text { ABORDAGEM DO ESPAÇO URBANO }\end{array}$ & SILVIO JOSÉ CONCEIÇÃO & $\begin{array}{l}\text { http://www.cinform- } \\
\text { anteriores.ufba.br/v_anais/a } \\
\text { rtigos/silviojoseconceicao.ht } \\
\mathrm{ml}\end{array}$ & $\begin{array}{l}\text { Propor uma visão em rede do } \\
\text { objeto cidade a partir de } \\
\text { reflexőes acerca dos fluxos } \\
\text { de informação ger(i)(a)dos } \\
\text { no espaço urbano como } \\
\text { possibilidade para a } \\
\text { construção do conhecimento }\end{array}$ & \begin{tabular}{|l} 
Revisão de \\
literatura
\end{tabular} & $\begin{array}{l}\text { Informação, cidade, } \\
\text { conhecimento redes, } \\
\text { espaços de fluxos e } \\
\text { abordagem urbana. }\end{array}$ \\
\hline 9 & $\begin{array}{l}\text { LUGARES E ESPAÇOS DA CIDADE: } \\
\text { artefatos infor-comunicacionais } \\
\text { memorialisticos }\end{array}$ & $\begin{array}{l}\text { Tahis Virginia Gomes da Silva } \\
\text { Maria Nilza Barbosa Rosas } \\
\text { José Mauro Matheus Loureiro }\end{array}$ & $\begin{array}{l}\text { XIX ENCONTRO NACIONAL } \\
\text { DE PESQUISA EM CIÊNCIA DA } \\
\text { INFORMAÇÃO-ENANCIB } \\
2018\end{array}$ & $\begin{array}{l}\text { Apresentar uma reflexão } \\
\text { sobre as inter-relaçôes } \\
\text { dialógicas do binômio } \\
\text { "informação e memória". }\end{array}$ & $\begin{array}{l}\text { Revisão de } \\
\text { literatura }\end{array}$ & \begin{tabular}{|l} 
MEMḾ́RIA: \\
referenciamento \\
INFORMAÇÃO: \\
representação \\
CULTURA: artefatos \\
A CIDADE: múltiplos \\
Iugares e espaços de \\
memória \\
\end{tabular} \\
\hline 10 & $\begin{array}{l}\text { A contribuição das redes sociais na } \\
\text { elaboração de políticas públicas } \\
\text { participativas }\end{array}$ & $\begin{array}{l}\text { Andrés Burgos Delgado Diana } \\
\text { Rocí Rodríguez Triana Doris } \\
\text { Aleida Villamizar Sayago }\end{array}$ & $\begin{array}{l}\text { Encontro Internacional } \\
\text { Participacăao, Democracia e } \\
\text { Políticas Públicas: } \\
\text { aproximando agendas e } \\
\text { agentes 23 a 25 de abril de } \\
\text { 2013, UNESP, Araraquara (SP) }\end{array}$ & $\begin{array}{l}\text { Analisar as políticas públicas } \\
\text { desde a perspectiva } \\
\text { relacional das redes sociais, } \\
\text { apresentando os principais } \\
\text { aspectos metodológicos- } \\
\text { conceituais embasados na } \\
\text { abordagem da policy } \\
\text { network, de modo a } \\
\text { contribuir para o odebate } \\
\text { sobre participaçăo, } \\
\text { democracia e olíticas } \\
\text { públicas, desde o } \\
\text { reconhecimento da } \\
\text { importância das relaçōes } \\
\text { sociais. }\end{array}$ & \begin{tabular}{|l} 
Revisão de \\
literatura
\end{tabular} & $\begin{array}{l}\text { O processo de formulação } \\
\text { de políticas públicas } \\
\text { A teoria de redes sociais } \\
\text { Policy network } \\
\text { Governança e políticas } \\
\text { públicas } \\
\text { A participação social na } \\
\text { gestão de políticas } \\
\text { públicas }\end{array}$ \\
\hline
\end{tabular}

Fonte: Elaborada pelos autores, 2019. 


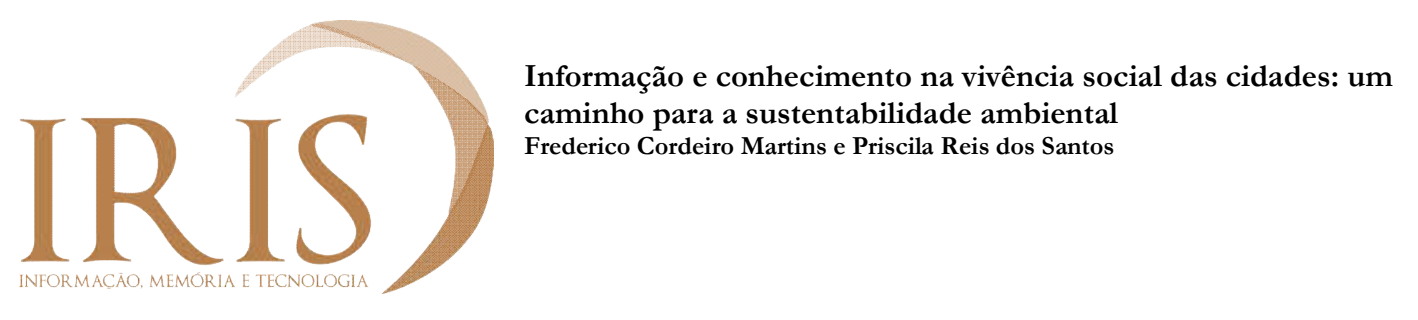

Posteriormente ao estudo dos temas foram elaborados apontamentos, estabelecendo uma correlação entre os termos, numa construção interdisciplinar de investigação detalhada do compartilhamento de pesquisas, experiências, objetivos e problemas como resposta às transformações sociais, políticas, culturais e tecnológicas que visam o aprimoramento das técnicas e instrumentos de aplicação prática em ciência, tecnologia e inovação na solução de problemas em diversos níveis.

\section{Referencial teórico}

\subsection{Informação e conhecimento na vivência social das cidades}

Quando se menciona o processo de tomada de decisões tem-se que esta deve ser baseada na informação e em seus diversos aspectos que vão desde a coleta até a disponibilização, passando pelos processos de agrupamento, cálculos, transformação etc, que acabam por gerar conhecimento a ser transformado em estruturas físicas para que possa assim ser utilizado.

Nas cidades o processo de tomada de decisões, ou como menciona Conceição (2018) "os caminhos da cidade" se confundem com aqueles "da informação e do conhecimento" onde não se sabe ao certo como são produzidas e, em que, ou quem, se baseia, tanto podendo surgir ao acaso, em razão do comportamento de um determinado grupo, como por imposição daqueles que detêm o poder político e de tomada de decisões que criam soluções que visam resolver problemas públicos, numa lógica conhecida como políticas públicas.

De acordo com Delgado (2013) “As políticas públicas são um conjunto inter-relacionado de decisões que têm como foco uma área determinada de conflito ou tensão social.” Já Conceição (2018) cita que "é tudo o que um governo faz e deixa de fazer, com todos os impactos de suas ações e de suas omissões" e as classifica como redistributivas, distributivas e regulatórias:

São políticas redistributivas as que fazem a redistribuição de renda como forma de recursos, São exemplos de políticas públicas redistributivas os programas de bolsa-escola, bolsa-universitária, cesta básica, renda cidadã, isenção de IPTU (imposto predial e territorial urbano) e de taxas de energia e/ou água para famílias carentes, dentre outros. As distributivas implicam em ações cotidianas, elas dizem respeito à oferta de serviços públicos e equipamentos. Por fim, o autor cita a política pública regulatória, essas consistem na elaboração das leis que autorizarão os governos fazer ou não determinada política pública redistributiva ou distributiva (CONCEIÇÃO, 2018, p.18). 


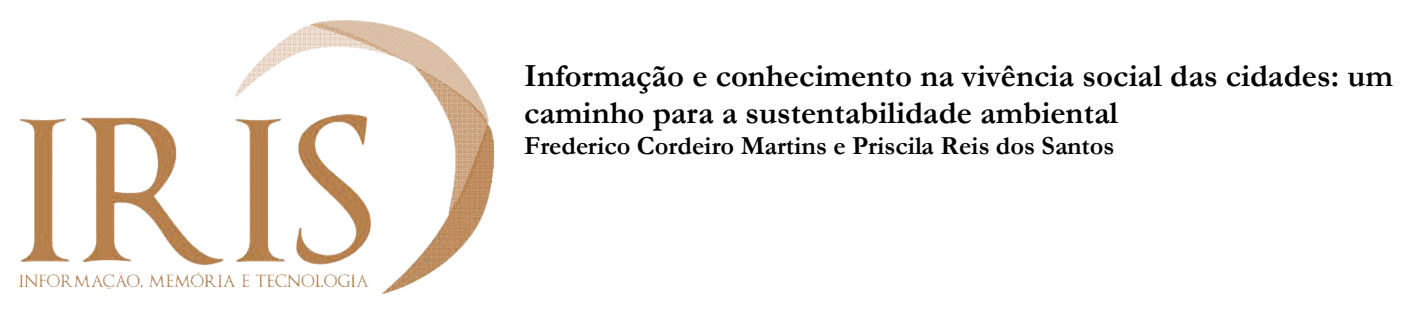

Conforme mencionam Silva e Pinheiro (2012) no livro Compartilhamento da Informação Tomael (2012, p. 77), “a elaboração de políticas públicas é dinâmica resultante de fenômenos sociais e históricos", ou seja, baseado no comportamento dos indivíduos que compõem certos setores da sociedade, para os quais se estabelece uma série de regras, diretrizes e planos, o que, em termos de resíduos sólidos, se reflete na Lei $n^{\circ}$ 12.305, publicada no ano de 2010, que estabeleceu a Política Nacional de Resíduos Sólidos - PNRS, trazendo em seu texto um conjunto de ações e regras para obtenção, direção, produção, divulgação e fluxo de informação sobre o tema.

Em seus objetivos, instrumentos e diretrizes, a Política Nacional de Resíduos Sólidos PNRS exige de cada cidade a elaboração de um plano pertinente, mediante processo de mobilização e participação social, incluindo a realização de audiências e consultas públicas.

A Constituição da República Federativa do Brasil (1988) consolidou uma nova ordem social de Estado Democrático de Direito que visa atender aos princípios da igualdade e da dignidade da pessoa humana, através de políticas públicas relacionadas a direitos sociais, sendo este um papel preponderante do Estado que, conforme será analisado neste artigo, apresenta certos vazios, lacunas que o cidadão tem buscado preencher através dos processos participativos, da reivindicação e do próprio fazer à medida que compartilham informação e conhecimento baseados nas suas experiências de vida em comunidade, por meio de ferramentas tecnológicas que os liguem em redes.

Nas cidades há uma complexa diversidade de fenômenos que surgem a partir das relações das pessoas entre si e com os demais elementos urbanos, produtores de conhecimento e informação baseado na vivência social do individuo, dos grupos, movimentos, rotinas, objetos, não podendo elas (cidades) serem consideradas apenas pelos seus aspectos formais e suas políticas focadas em pontos de tensão ou conflito.

Para considerar a cidade em todos os aspectos é importante trabalhar com a sistemática de rede, para alcançar todo seu potencial, especialmente aquele gerado a partir da própria vivência social e de uma identidade informacional própria baseada nas experiências e no cotidiano das pessoas e suas interações que o ambiente que as cercam, posto que a mera informação sobre determinado objeto não produz conhecimento sem que se estabeleça uma relação dialógica entre sujeito e objeto, conforme destacam Silva e Pinheiro (2012) no livro Compartilhamento da Informação (TOMAEL, 2012, p. 77).

Compreende-se que as cidades, por si só, pela sua própria força social, apontam os caminhos para a solução de seus próprios problemas e melhoria da qualidade de vida de maneira sustentável 


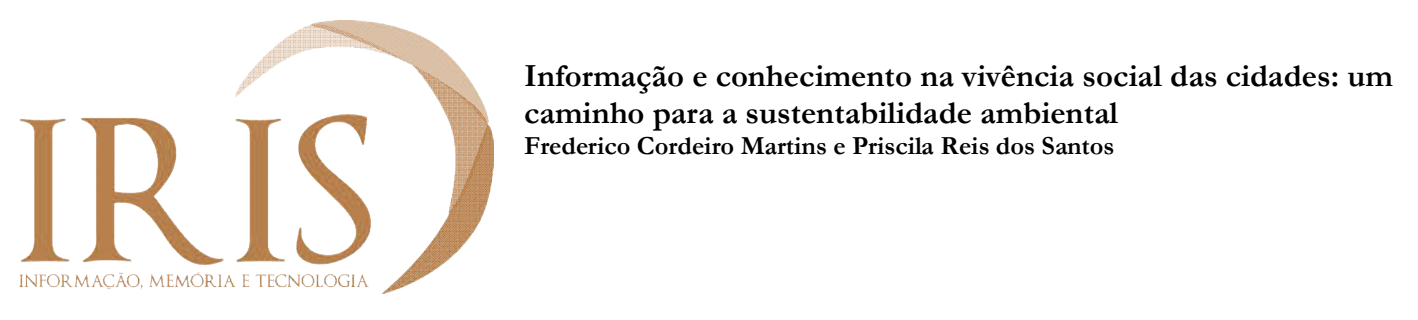

em todos os seus aspectos, baseados em seus estoques de informação e relacionamentos em redes formais e informais amparados pelos meios tecnológicos de informação e comunicação que possuem relevância prática e efetiva no cotidiano das pessoas.

Silveira et al. (2018) destacam que o planejamento e a gestão que tenham por base a participação popular podem contribuir para a redução dos crescentes impactos gerados pela acelerada urbanização o que tem desencadeado no que chamam de "desgovernança" das instituições políticas, o que entendemos como vazios institucionais.

Não se pode determinar mediante elementos precisos como o surgimento de determinadas soluções para os problemas ambientais acontece, sendo certo que se trata de um fenômeno marcado pelo desenvolvimento social e as novas necessidades de convívio no ambiente urbano, aliado às tecnologias da informação e comunicação (TICs).

Em "Emergência: a vida integrada de formigas, cérebros, cidades e softwares", Steven Johnson cita que uma pesquisa de campo realizada com o objetivo de conhecer o comportamento das formigas cortadeiras do sudoeste dos Estados Unidos aponta para um impressionante comportamento descentralizado da natureza onde "inteligência, personalidade e aprendizado emergem de baixo para cima, bottom-up.” (JOHNSON, 2003) e cita:

\begin{abstract}
"Os críticos de questões urbanas desde Lewis Mumford e Jane Jacobs sabem que as cidades tem vida própria, com bairros se povoando sem nenhuma figura de Robert Moses para impor um plano a partir de cima. Porém, só recentemente a compreensão desse fato entrou no pensamento intelectual - quando Engels caminhou pelas ruas de Manchester na década de 1840, ele ficou tateando como um cego, tentando encontrar um culpado para a perversa organização da cidade, mesmo sabendo que ela, reconhecidamente, não tivera um planejamento" (p. 27-28).
\end{abstract}

Pelo olhar atento de Johnson (2003) não são necessárias regras e projetistas urbanos para criar as estruturas e garantir o funcionamento de uma cidade, basta apenas a presença de alguns milhares de indivíduos e algumas regras simples de interação, num movimento natural onde uma loja elegante atrai outras ainda mais elegantes e acabam empurrando os mais pobres para os locais mais escondidos, onde se formam naturalmente, sem planejamento, as aglomerações, vilas, favelas.

Assim, verificamos que a força na cidade não reside apenas no planejamento estruturado pelas instituições políticas, mas também da forma das pessoas, que, atualmente se aliam às tecnologias de informação e conhecimento para, a partir das suas vivências sociais, criarem um laço 


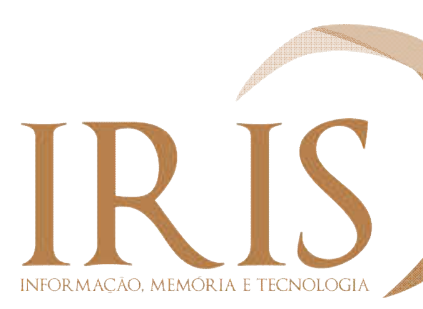

Informação e conhecimento na vivência social das cidades: um

caminho para a sustentabilidade ambiental

Frederico Cordeiro Martins e Priscila Reis dos Santos

de união formando uma identidade informacional capaz de transformar o ambiente que vivem, criando melhores condições de vida e garantindo a sustentabilidade ambiental.

Com grande capacidade de expressão e pressão políticas baseada nas redes de interesse da internet, revisão das pautas da imprensa e outros meios de comunicação, a população se capacita para construção de agendas. São mecanismos que ela (população) utiliza para aumentar sua capacidade de reivindicação direta de uma forma que até este momento não se conhecia (POLIZELLI, 2011).

Neste sentido as decisões de caráter politico-estatal, baseadas em políticas de informação no âmbito do Estado para a concretização de políticas públicas voltadas para o desenvolvimento das cidades e suas consequências para as instituições e para a sociedade, vem surgindo a partir de um novo cenário ditado pelos indivíduos que a compõem através de uma nova realidade amparada pela tecnologia.

Ocorre que há um universo de informações difusas que não são devidamente exploradas com o objetivo de criar novas agendas de discussão sobre políticas públicas. Ferramentas tecnológicas de informação podem transformar o Estado, considerando a multiplicidade de atores envolvidos na produção de redes formais ou informais de diversos canais, entidades, usuários etc.

A informação é fenômeno social, uma atividade produtiva que promove o desenvolvimento do sujeito, uma forte força de transformação (SILVA et al., 2018).

Citando Frohmann, Kerr Pinheiro (2012) destaca a necessidade de que as políticas partam de um regime de informação:

Conjunto mais ou menos estável de redes formais e informais nas quais as informações são geradas, organizadas e transferidas de diferentes produtores, através de muitos e diversos meios, canais e organizações, a diferentes destinatários ou receptores de informação. (p. 9).

Assim sendo, compreendemos que o desenvolvimento das cidades e alcance das melhorias necessárias a um convívio social adequado depende de um processo de construção permanente em torno da informação e do conhecimento onde as mudanças acontecem para haja plena adaptação ao contexto social vivenciado pelas pessoas.

O uso de ferramentas tecnológicas cria possibilidades de interação, participação e capacitação da sociedade para que assim se articulem em torno das políticas públicas de interesse comum, conforme destacam (COSTA; MENEZES, 2016, p. 338): 


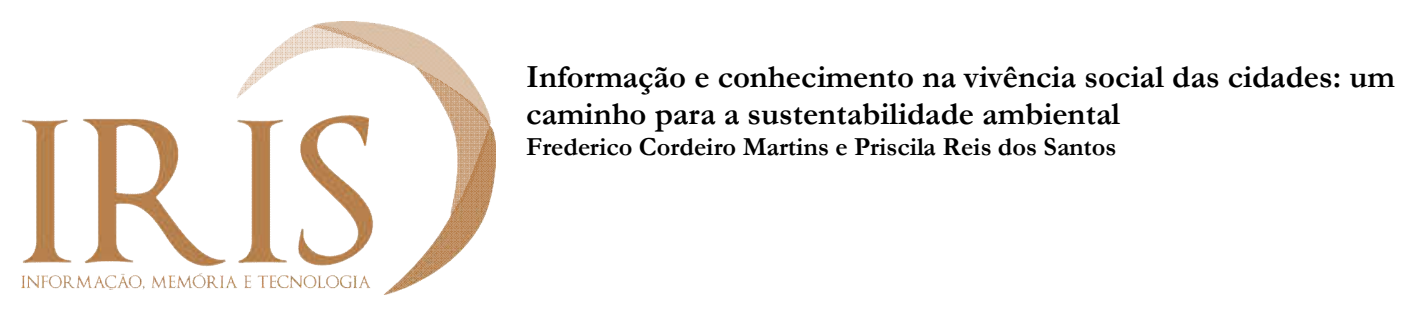

\begin{abstract}
Além das TIC serem uma importante ferramenta para a construção de cenários e de simulações, quando usadas para a comunicação social podem ajudar a reforçar a atratividade, a divulgação de informação sobre o próprio espaço, os seus equipamentos e serviços, bem como sobre as atividades desenvolvidas em espaços públicos específicos. Essa interação entre utilizadores do espaço e das TIC pode também contribuir para o compartilhamento de informações, a exposição de opiniões, de necessidades e de desejos relativamente ao espaço público [...].
\end{abstract}

A evolução da sociedade implica no surgimento de novos focos de discussão política e formação de novas agendas na ordem Estatal.

Neste sentido, em termos de políticas públicas socioambientais, em especial aquelas direcionadas para a gestão de resíduos sólidos e sua aplicação em benefício das cidades, observa-se que há uma série de questões ainda não trabalhadas. Na visão de Philippi Jr. (2013, p. 695) uma autêntica política pública é aquela que cria condições de equilíbrio entre as ações do governo e as aspirações da sociedade, com vistas ao bem comum.

Ainda de acordo com Philippi Jr. (2013, p. 681), as transformações culturais e tecnológicas tem demonstrado um empobrecimento das instituições políticas, que estimula o rompimento dos vínculos de dependência do Estado e de suas políticas, onde as pessoas vem se antecipando às proposições legislativas na busca pela conservação dos direitos.

Porém para que estas perspectivas sejam apresentadas de maneira mais coerente e consistente, partindo da origem dos problemas, como aqueles vivenciados pelas pessoas que convivem no ambiente das cidades, para as quais estas são destinadas, conforme destaca Jan Gehl ao longo de seu livro intitulado "Cidades Para Pessoas", que se integram e trocam informações e experiências que em grande maioria dos casos não conduzem a resultados positivos em termos de políticas públicas uma vez que são concebidas de cima pra baixo.

Costa e Menezes (2016, p. 338) sustentam que "as novas tecnologias, suas aplicações e dispositivos também estão permitindo uma variada gama de oportunidades para melhor compreensão dos contextos, para o compartilhamento de informação e do conhecimento, permitindo a descoberta e o apoderamento da cidade."

\title{
3.2 Gestão de resíduos sólidos, vazios institucionais e a sustentabilidade ambiental
}




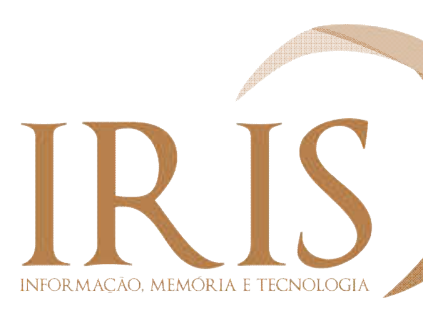

Informação e conhecimento na vivência social das cidades: um

caminho para a sustentabilidade ambiental

Frederico Cordeiro Martins e Priscila Reis dos Santos

Em consonância com o disposto na Constituição Federal, Milaré (2015) destaca que o meio ambiente é de interesse comum, independentemente da existência de garantias de propriedade e de limites geopolíticos. Por tal motivo, de acordo com Silva (2017), o direito ambiental visa proteger a qualidade do meio ambiente em função da qualidade de vida, sendo que há dois objetos de tutela, no caso: um imediato - que é a qualidade do meio ambiente, e o outro mediato - que é a saúde, o bemestar e a segurança da população, que se vem sintetizando na expressão qualidade de vida.

A ocorrência de diversos fenômenos ecológicos, todos tendentes a desequilibrar o meio ambiente, causando danos por vezes irreparáveis, despertou a consciência ambientalista, chamando a atenção das autoridades para esta problemática (SILVA, 2017).

Philippi Jr. et al. (2013, p. 700) conceituam a gestão ambiental como sendo o ato de administrar, de dirigir ou reger os ecossistemas naturais e sociais em que o homem se insere e com ele busca uma interação com as atividades que exerce. Para isso é necessário estabelecer padrões de qualidade que primam pela preservação, manutenção ou recuperação do ambiente natural.

Já Dias (2017, p. 89) conceitua gestão ambiental como sendo a gestão empresarial que se orienta a evitar, na medida do possível, problemas para o meio ambiente. Ou seja, é a gestão que objetiva conseguir que os efeitos ambientais não ultrapassem a capacidade de carga do meio onde se encontra a organização, obtendo-se um desenvolvimento sustentável. Este autor complementa que o processo de gestão ambiental nas empresas encontra-se profundamente vinculado às normas legais elaboradas pelas instituições públicas que disciplinam a ordem jurídica do meio ambiente, sendo o principal instrumento para se obter um desenvolvimento industrial sustentável.

A gestão ambiental é, pois, a ferramenta utilizada pelo homem para fazer uso racional do meio ambiente, com o melhor aproveitamento de seus recursos, para não lhe causar danos, bem como para mitigar aqueles que foram gerados pela sua exploração. As normas legais são referências obrigatórias para as empresas que pretendem implantar um Sistema de Gestão Ambiental (SGA), sendo que a violação de tais normas legais, ou seu desconhecimento, afeta de forma significativa os investimentos das empresas, como também sua capacidade de intervenção no mercado (DIAS, 2017).

Dias (2017, p. 91) conceitua o Sistema de Gestão Ambiental, como sendo: 1)Conjunto de responsabilidades organizacionais, procedimentos, processos e meios que se adotam para a implementação de uma política ambiental em determinada empresa ou unidade produtiva; 2) Sistematização da gestão ambiental por uma organização determinada; 3) É todo empregado para 


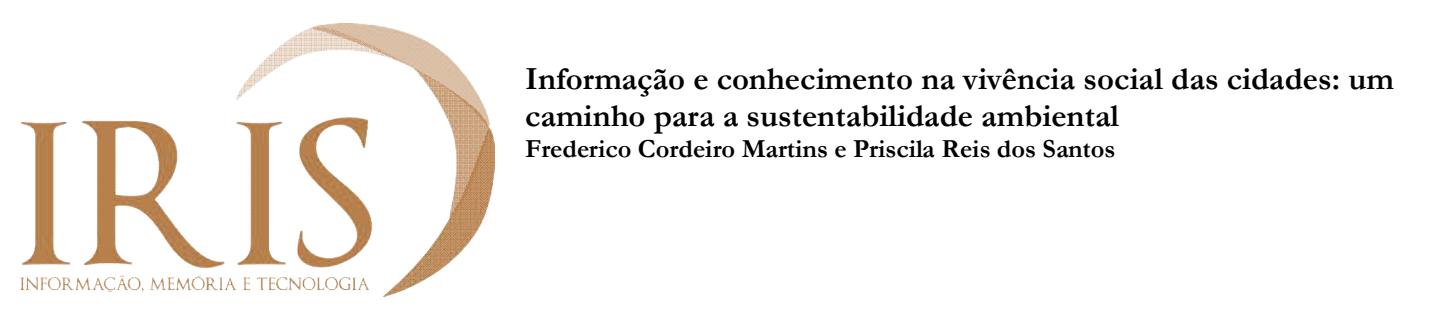

levar uma organização a atingir e manter-se em funcionamento de acordo com as normas estabelecidas, bem como para alcançar os objetivos definidos em sua política ambiental.

Sabe-se que a geração de resíduos sólidos é tema preocupante no dia-a-dia das cidades, mas que tem ganhado contornos mais relevantes diante da crescente conscientização das pessoas em relação às questões ambientais, especialmente no que diz respeito à preservação dos recursos naturais, saúde e bem estar social, sob a ótica do desenvolvimento sustentável.

Neste contexto, Klein et al. (2018) ressaltam que um dos maiores desafios da atual gestão brasileira de resíduos sólidos é o de eliminação da destinação final inadequada, considerando que, até então, a maioria dos municípios ainda destina seus resíduos em lixões ou aterros controlados que geram diversos impactos ambientais negativos.

É relevante destacar que a adequada gestão de resíduos sólidos deve ser pautada em soluções para as causas elementares dos problemas, com a adoção de métodos que garantam a sustentabilidade desde a produção e consumo até a redução, reutilização, reciclagem e tratamento, além da disposição final dos rejeitos, ou seja, tem que contemplar abrange todo o ciclo que se inicia com a geração do resíduo e vai até a disposição final dos rejeitos.

É de se destacar, ainda que a gestão de resíduos sólidos, que não pode ser generalista, ou seja, deve considerar as especificidades regionais, cria uma necessidade de integração de diversos atores sociais além das autoridades públicas, como a sociedade civil e as instituições privadas.

Em estudo comparativo com cidades europeias, Mannarino et al. (2016) sustentam que o sistema de gestão de resíduos sólidos deve integrar toda sua cadeia de descarte, coleta, transporte, tratamento e destinação final à estrutura urbana local onde se insere, com destaque para o fato de que o local de destino dos resíduos não deve ser apenas um ponto de confinamento geograficamente distante da população, mas, sim, um local onde eles poderão estar reinseridos no seu ciclo ambiental, permitindo um convívio harmonioso entre as pessoas e o lixo por elas produzidos, evitando, desta forma o surgimento de graves problemas que venham afetar a sociedade. Cuidar do meio ambiente é também pensar nas pessoas como tal, afinal, gente também é natureza.

Do ponto de vista do desenvolvimento sustentável é importante mencionar que qualquer sistema, forma ou plano de gestão de resíduos sólidos deve ser capaz de suprir as necessidades da geração atual, sem comprometer a capacidade de atender as necessidades das futuras gerações, na busca de um equilíbrio entre desenvolvimento e crescimento econômico, que, invariavelmente 


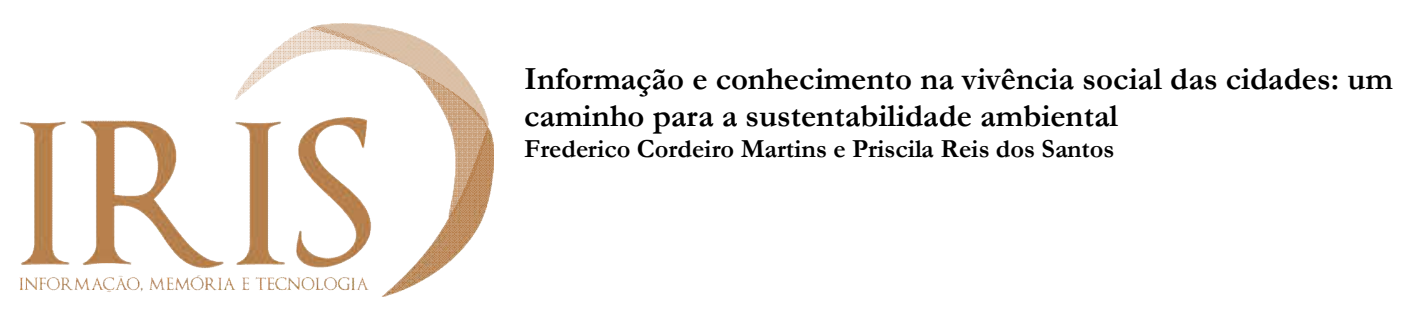

necessita do consumo de recursos naturais, que tem característica finita, por meio da diminuição do emprego de recursos e consumo de produtos, além do aumento da reutilização e da reciclagem.

A complexidade que envolve o desenvolvimento sustentável carece de um equilíbrio entre as dimensões social, ambiental e econômica da sustentabilidade. Neste sentido, embora a dimensão econômico-financeira apresente-se ainda como a função-objetivo na grande maioria das organizações, nas últimas décadas observa-se o aumento substancial da relevância da dimensão social, motivada em grande parte por mudanças expressivas no ambiente que cercam as pessoas e suas diversas formas de interação.

Conforme já mencionado o aumento no volume de resíduos sólidos cresceu três vezes mais que o crescimento populacional, o que leva ao entendimento de que grande parte das cidades ainda não consegue ser autossustentável dada as altas taxas de consumo dos recursos naturais e da grande descarga de resíduos (MILLER JR., 2007).

Via de regra, compete às instituições políticas representadas pelo Estado, determinadas pelas leis, regras, políticas públicas, normas formais ou informais que podem influenciar o comportamento dos indivíduos, a criação de mecanismos que permitam que o processo de gestão dos resíduos sólidos da cidade seja capaz de garantir um ambiente urbano limpo, salubre e agradável para se viver. Conforme destacam (SOUSA E SILVA; TRAVASSOS, 2008):

\begin{abstract}
Nos países em desenvolvimento e, especialmente no Brasil, pode-se dizer que a institucionalização da questão ambiental urbana não apresentou reflexos concretos nas cidades. Há uma distância considerável entre o discurso contido nas agendas e documentos e a realidade socioambiental dessas cidades, que resulta, dentre outros, da incapacidade de conceber políticas públicas que levem em conta não somente o efeito - degradação ambiental, social e urbana -, mas também suas causas - as formas de produção do espaço urbano. Esse distanciamento também decorre do imenso passivo socioambiental existente nessas cidades, onde os problemas de degradação socioambiental estão muito além da capacidade de seu equacionamento. (p. 28)
\end{abstract}

Assim, para garantir uma resposta inteligente aos problemas locais, a participação nos projetos inteligentes deve ser integrada em uma parceria entre a comunidade, empresas, governo, acadêmicos, conforme destacado por Kerr Pinheiro (2017), o que, por muitas vezes não acontece, deixando falhas no processo institucional, Institutional Voids (RODRIGUES, 2013).

Institutional Voids é um conceito que surgiu a partir de estudos desenvolvidos na Universidade de Harvard, Estados Unidos, no ano de 2005 e representa a imperfeições institucionais entre as regras formais e informais e sua repercussão no funcionamento dos mercados e seus impactos 


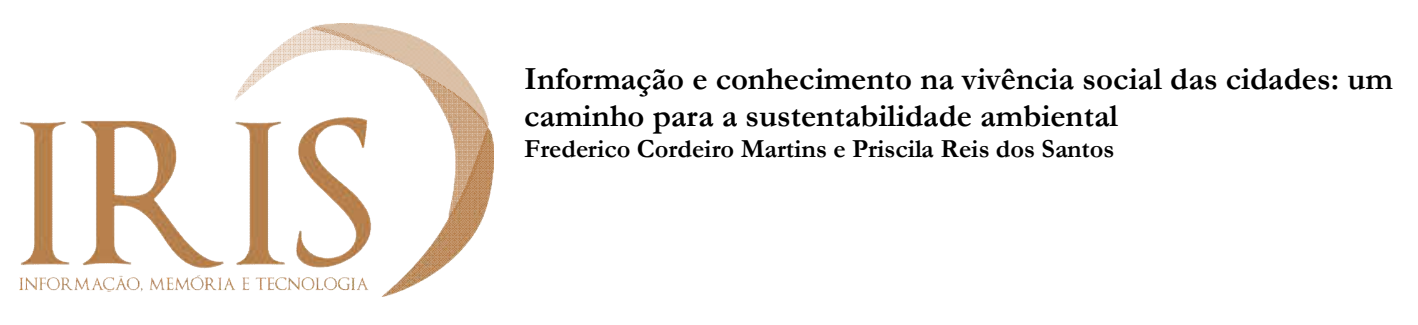

negativos no desempenho das empresas, onde a instabilidade do sistema político cria um cenário desfavorável ao empreendedorismo, mas que, também, por outro lado gera oportunidades de inovação, conforme observado por Khanna e Palepu (2005), ou seja, é um sistema de caráter dúplice, que tanto pode apresentar aspectos negativos quanto positivos.

Rodrigues (2013) destaca como as instituições políticas, considerando os seus mecanismos de implementação e controle, permitem o surgimento dos Institutional Voids. Esta percepção surge até mesmo do fato das pessoas se resignarem, de certa forma, à obediência das normas, especialmente em um cenário de inexistência de um sistema institucional capaz de garantir o seu cumprimento.

\section{Considerações finais}

A geração de resíduos sólidos é tema problemático e gravemente preocupante se considerarmos os fatores já elencados, em especial o crescimento populacional e o curto ciclo de consumo de produtos.

Um grande volume de lixo é produzido diariamente no mundo todo, colocando as cidades e as pessoas, cuja participação no processo de tomada de decisões é fundamental, no centro das discussões a respeito do tema.

É importante desatacar que as pessoas tem, cada vez mais, se tornado protagonistas de mudança nos cenários sociais e políticos por meios tecnológicos e redes de informação e conhecimento como forma de preencher as lacunas deixadas pelo poder público.

Conforme já mencionado, não se sabe ao certo como surgem esses movimentos, explicação que não se encontra na pesquisa aqui elaborada por se tratar de um fenômeno social que se expande de uma maneira rápida através da dinâmica das redes de informação e conhecimento.

Exemplo disto é o chamado "desafio do lixo" em inglês "trashtag challenge", onde as pessoas são motivadas à prática de ações de limpeza de locais que acumulam certa quantidade de lixo, postando nas redes sociais fotos e/ou vídeos do "antes" e "depois". 


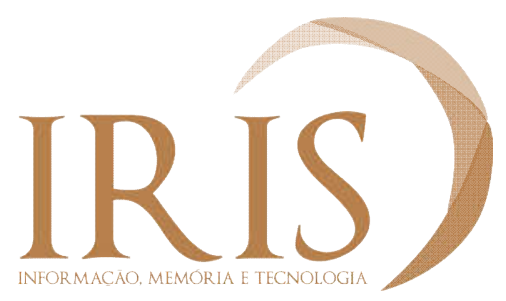

Informação e conhecimento na vivência social das cidades: um caminho para a sustentabilidade ambiental

Frederico Cordeiro Martins e Priscila Reis dos Santos

Figura 1 - Postagens trashtag challenge
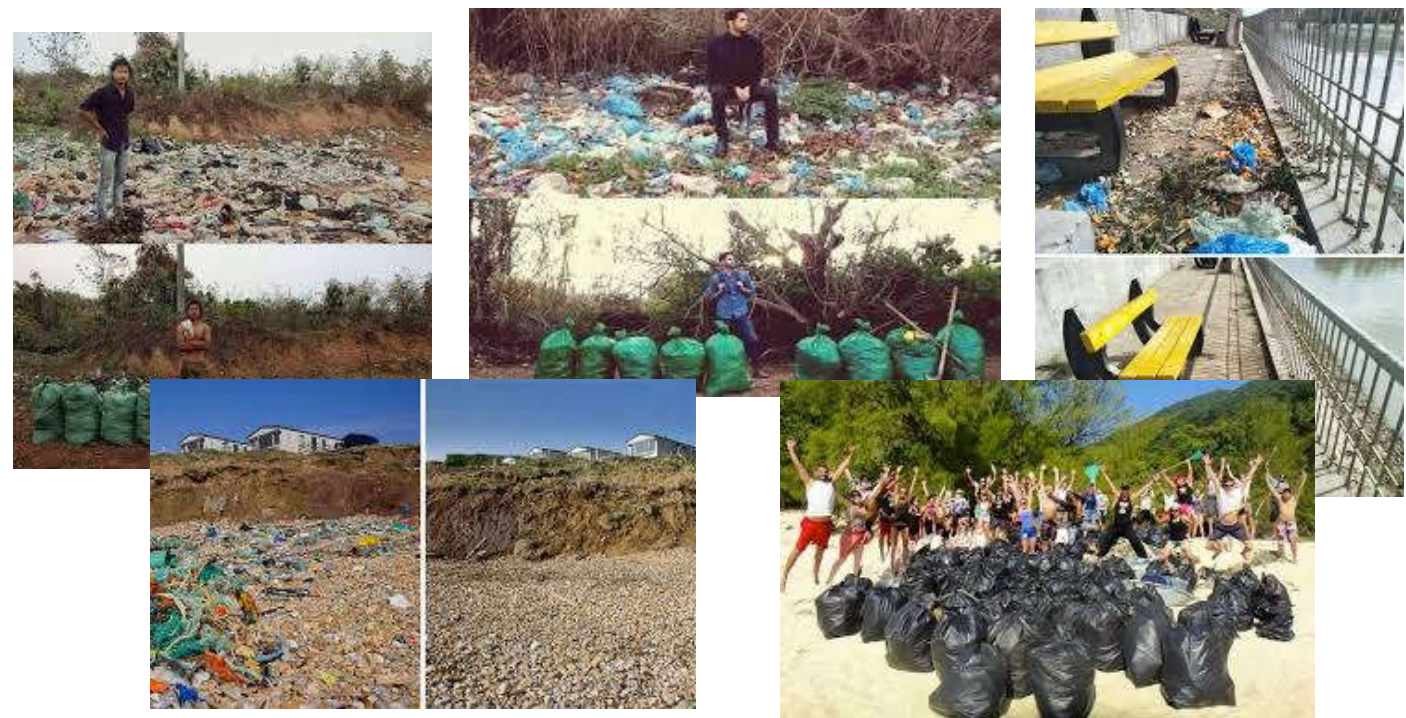

Fonte: Instagram, 2019.

Podem-se destacar também as ações voltadas para a conscientização das pessoas quanto à redução e adequação do consumo de produtos que aumentam a geração dos resíduos sólidos, bem como daquelas relacionadas com o seu adequado descarte, como os perfis do Instagram "Um ano sem lixo", "Por favor menos lixo", "Jornada zero waste" etc.

São ações pontuais que contribuem para o gerenciamento e controle dos resíduos sólidos, mas não são perenes, como as políticas públicas, que visam garantir a continuidade do gerenciamento dos resíduos sólidos em todas as suas etapas.

Tais evidências nos levam ao entendimento de que as pessoas, suas informações e seu conhecimento, cuja origem reside em suas próprias experiências sociais, acabam por exercer como papel fundamental uma pressão normativa nas instituições encarregadas da elaboração de políticas públicas voltadas ao atendimento de suas necessidades, que induz a uma resposta quanto à proteção ao meio ambiente que, segundo Dias (2017, p. 47) se caracteriza "na pressão normativa de padrões estabelecidos" e interfere diretamente no processo decisório das instituições políticas quanto às boas práticas ambientais.

Assim verificamos que existem diversas abordagens da vivência social nas cidades que, baseadas nas tecnologias de informação e conhecimento, transformam as políticas públicas ambientais em planejamento, ação, controle e avaliação. 


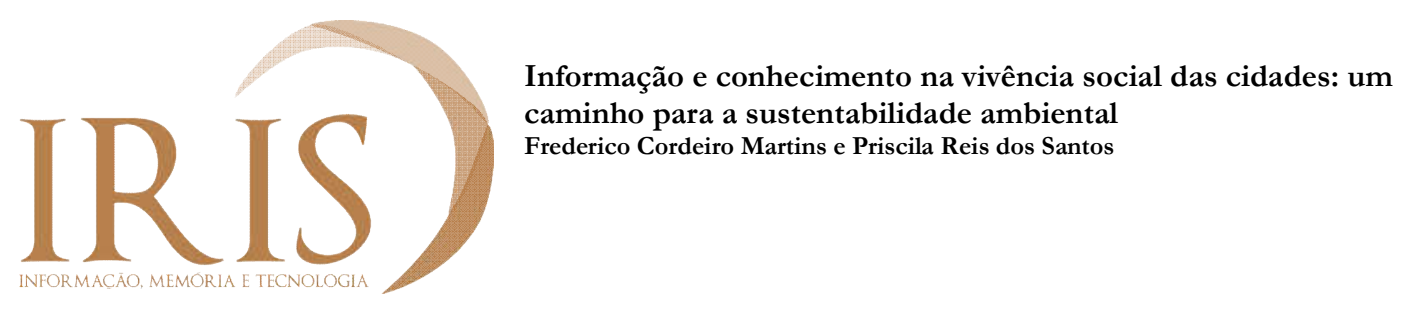

São estudos científicos que contribuem para a ciência da informação e apontam para uma crescente participação política dos sujeitos que contribuem para a gestão de resíduos sólidos nas cidades a partir de sua vivência social, preenchendo as lacunas omissivas das instituições na elaboração de políticas públicas que garantam a sustentabilidade ambiental.

\section{Referências}

AGOSTINI, Manuela Rösing; VIEIRA, Luciana Marques; BOSSLE, Marilia Bonzanini. Social innovation as a process to overcome institutional voids: a multidimensional overview. RAM, Rev. Adm. Mackenzie, São Paulo, v. 17, n. 6, p. 72-101, dez. 2016. DOI http://dx.doi.org/10.1590/1678-

69712016/administracao.v17n6p72-101. Disponível em:

http://www.scielo.br/scielo.php?script=sci_arttext\&pid=S1678-69712016000600072\&lng=en\&nrm=iso. Acesso em: 08 mar. 2019.

ASSOCIAÇÃO BRASILEIRA DE EMPRESAS DE LIMPEZA PÚBLICA E RESÍDUOS ESPECIAIS ABRELPE. Panorama 2017. Disponível em: http://abrelpe.org.br/download-panorama-2017/. Acesso em: 20 de nov. 2018.

BRASIL. Política Nacional de Resíduos Sólidos, lei $\mathbf{n}^{\mathbf{0}}$ 12.305, de 2 de agosto de 2010. Disponível em: http://www.planalto.gov.br/ccivil_03/_Ato2007-2010/2010/Lei/L12305.htm. Acesso em 20 de nov. 2018.

TOMAÉL, Maria Inês (org.). Compartilhamento da informação. Londrina: Eduel, 2012. CONCEIÇÃO, Silvio José. Informação, cidade e conhecimento: Por uma abordagem do espaço urbano. Disponível em http://www.cinform-anteriores.ufba.br/v_anais/artigos/silviojoseconceicao.html. Acesso em 05 out.2018.

COSTA, Carlos Smaniotto; MENEZES, Marluci. A agregação das Tecnologias de Informação e Comunicação ao espaço público urbano: reflexões em torno do Projeto CyberParks - COST TU 1306. urbe, Rev. Bras. Gest. Urbana, Curitiba, v. 8, n. 3, p. 332-344, dez. 2016. Disponível em: http://www.scielo.br/scielo.php?script=sci_arttext\&pid=S2175-33692016000300332\&lng=en\&nrm=iso. Acesso em 08 mar. 2019.

DELGADO, Andrés Burgos; TRIANA, Diana Rocío Rodríguez; SAYAGO, Doris Aleida Villamizar. A contribuição das redes sociais na elaboração de políticas públicas participativas. Encontro Internacional Participação, Democracia e Políticas Públicas: aproximando agendas e agentes 23 a 25 de abril de 2013, UNESP, Araraquara (SP).

DEPINÉ, Ágatha Cristine. Fatores de atração e retenção da classe criativa: o potencial de Florianópolis como cidade humana inteligente. 2016. Dissertação (Mestrado em Engenharia e Gestão do Conhecimento) - Universidade Federal de Santa Catarina, Santa Catarina, 2016.

DIAS, Reinaldo: Gestão ambiental: responsabilidade social e sustentabilidade. 3. ed. São Paulo: Atlas, 2017. 


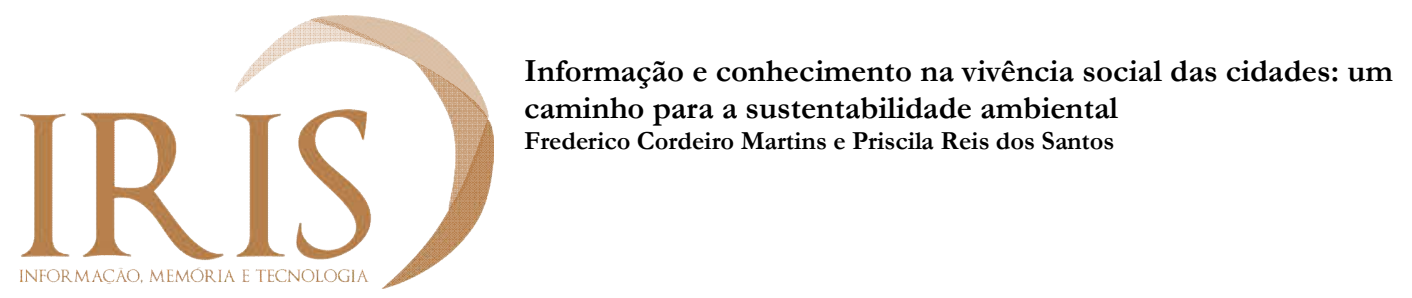

GARCIA E SILVA, Hermann Bergmann, OLIVEIRA LEITE, Hudson e KERR PINHEIRO, Marta Macedo. A dualidade das cidades inteligentes: melhoria da qualidade de vida ou controle informacional? Inf. \& Soc.:Est., João Pessoa, v. 26, n. 3, p. 47-54, set./dez. 2016.

GEHL, Jan. Cidades Para Pessoas; tradução Anita Di Marco. 3. ed. São Paulo: Perspectiva, 2015.

JOHNSON, Steven. Emergência: a vida integrada de formigas, cérebros, cidades e softwares. Rio de Janeiro: Jorge Zahar Ed., 2003.

KERR PINHEIRO, Marta Macedo. Cidades inteligentes no estado informacional: as dimensões políticas. In: XVIII ENCONTRO NACIONAL DE PESQUISA EM CIÊNCIA DA INFORMAÇÃO, 28., 2017, Marília. Anais eletrônicos [...]- Marília: UNESP, 2017. Disponível em: http://enancib.marilia.unesp.br/index.php/xviiienancib/ENANCIB/paper/view/393. Acesso em: 18 ago. 2018.

KERR PINHEIRO, Marta Macedo. Estado informacional, implicações para as políticas de informação e de inteligência no limiar do século XXI. Varia História, Belo Horizonte, vol. 28, n. 47, p.61-77, jan./jun. 2012.

KHANNA, T. E PALEPU, K. G. e SINHA, J. Strategles that fit emerging markets. Harvard Busines Review. 2005.

KLEIN, Flávio Bordino; GONCALVES-DIAS, Sylmara Lopes Francelino; JAYO, Martin. Gestão de resíduos sólidos urbanos nos municípios da Bacia Hidrográfica do Alto Tietê: uma análise sobre o uso de TIC no acesso à informação governamental. Rev. Bras. Gest. Urbana, Curitiba, v. 10, n. 1, p. 140-153, abr. 2018. Disponível em: http://www.scielo.br/scielo.php?script=sci_arttext\&pid=S217533692018000100140\&lng=en\&nrm=iso. Acesso em: 08 mar. 2019.

MADEIRA, Gilberto dos Santos; GUIMARAES, Tor; MENDES, Leonardo de Souza. Construindo governança eletrônica de cidades: Um modelo de implementação de soluções para inovação e otimização da gestão pública. RGPLP, Lisboa, v. 16, n. 2, p. 55-71, set. 2017. Disponível em: http://www.scielo.mec.pt/scielo.php?script=sci_arttext\&pid=S164544642017000200005\&lng=pt\&nrm=iso. Acesso em: 08 mar. 2019.

MANNARINO, Camille Ferreira; FERREIRA, João Alberto; GANDOLLA, Mauro. Contribuições para a evolução do gerenciamento de resíduos sólidos urbanos no Brasil com base na experiência Europeia. Eng Sanit Ambient, v. 21, n. 2, p. 379-385, abr./jun. 2016. Disponível em:

http://www.scielo.br/pdf/esa/2016nahead/1809-4457-esa-S1413_41522016146475.pdf. Acesso em: 08 mar. 2019.

MARANHÃO, Tatiana de P. A. Produção Interdisciplinar de Conhecimento Científico no Brasil: temas ambientais. Revista Sociedade e Estado, v. 25, n. 3, set./dez. 2010.

MILARÉ, Édis. Direito do ambiente: doutrina, prática, jurisprudência, glossário. 10. ed. São Paulo: Revista dos Tribunais, 2015.

MILLER JR., G. Tyler. Ciência ambiental. São Paulo: Thomson Pioneira, 2007.

ORGANIZAÇÃO DAS NAÇÕES UNIDAS-ONU. Nova Agenda Urbana. Disponível em: http://habitat3.org/the-new-urban-agenda/. Acesso em: 14 de setembro de 2018. 


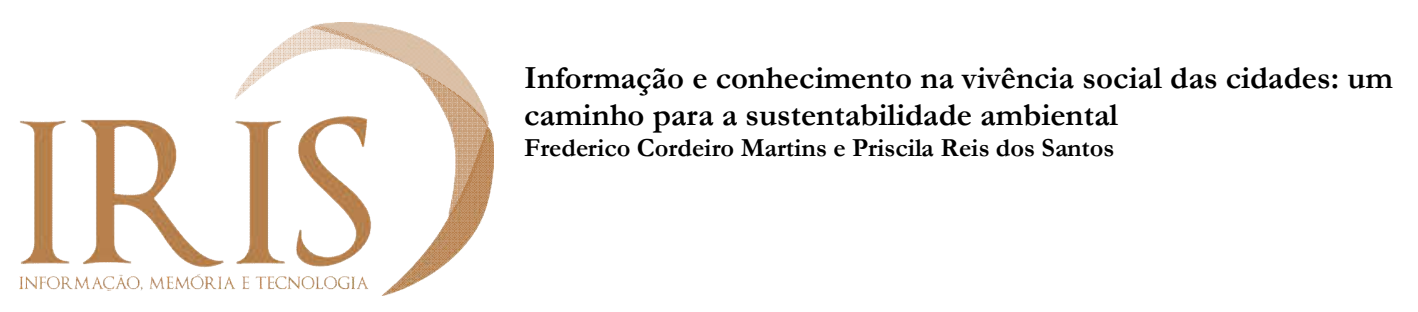

PHILIPPI JÚNIOR, Arlindo; ROMÉRO, Marcelo de Andrade; BRUNA, Gilda Collet. Curso de gestão ambiental. 2. ed. Barueri: Manole, 2013.

POLIZELLI, Demerval Luiz. Meio ambiente e gestão do conhecimento: dos higienistas à sociedade da informação. São Paulo: Almedina, 2011.

RODRIGUES, S. B. Understanding the environments of emerging markets: the social costs of institutional voids. ERIM Farewell Address - Series Research in Management. jun. 2013. Disponível em: repub.eur.nl/pub/40429/40429.pdf. Acesso em: 18 ago. 2018.

SILVA, Tahis Virginia Gomes da; ROSAS, Maria Nilza Barbosa; LOUREIRO José Mauro Matheus. Lugares e espaços da cidade: artefatos infor-comunicacionais memorialísticos. In: XVIII ENCONTRO NACIONAL DE PESQUISA EM CIÊNCIA DA INFORMAÇÃO, 28., 2017, Marília. Anais eletrônicos [...]- Marília: UNESP, 2017. Disponível em: http://enancib.marilia.unesp.br/index.php/XIXENANCIB/xixenancib/paper/view/1296. Acesso em: 08 mar. 2019.

SILVEIRA, Raquel Maria da Costa; FIGUEIREDO, Fábio Fonseca; ALMEIDA, Jelisse Vieira Gomes. A proteção ambiental e a gestão compartilhada: um estudo de caso na Região Metropolitana de Natal. Cad. Metrop., São Paulo, v. 20, n. 42, p. 513-530, ago. 2018. Disponível em: http://www.scielo.br/scielo.php?script=sci_arttext\&pid=S2236-99962018000200513\&lng=pt\&nrm=iso. Acesso em: 08 mar. 2019.

SOUSA E SILVA, Lucia; TRAVASSOS, Luciana. Problemas ambientais urbanos: desafios para a elaboração de políticas públicas integradas. Cadernos Metrópole, São Paulo, n. 19, p. 27-47, jan./jun. 2008.

TAMBELLI, Clarice Nassar. Smart Cities: uma breve investigação crítica sobre os limites de uma narrativa contemporânea sobre cidades e tecnologia. Disponível em: https://itsrio.org/wp-

content/uploads/2018/03/clarice_tambelli_smartcity.pdf. Acesso em: 09 set. 2018.

TOWNSEND, A. Smart Cities: Big Data, Civic Hackers, and the Quest for a New Utopia. New York: W.W. Norton \& Company, 2013.

WENDLER, R. The maturity of maturity model research: A systematic mapping study. Information and software technology, v. 54, n. 12, p. 1317-1339, 2012. Disponível em:

http://www.sciencedirect.com/science/article/pii/S0950584912001334. Acesso em: 23 mar. 2019.

Data de submissão: 03 de julho de 2019.

Data de aceitação: 26 de dezembro de 2019.

1 Disponível em: http://www.un.org/en/sections/issues-depth/population/index.html. Acesso em 24 de março de 2019. 